\title{
DESARROLLO Y CONSECUENCIAS DE LA GLOBALIZACION FINANCIERA
}

\author{
Aleksandro Palomo Garrido \\ EMUI_UCM, Universidad de Colima, México
}

http://dx.doi.org/10.5209/rev_NOMA.2012.v35.n3.42207

\begin{abstract}
Resumen.- El proceso de globalización logró abrir nuevos espacios que favorecieron la expansión financiera y económica. Esta expansión financiera se tradujo en un crecimiento económico durante la década de los noventa. De esta manera, los excedentes de capital acumulados, que estaban amenazados por la depreciación, encontraron posibilidades de inversión rentable en la ampliación del proceso de globalización. Sin embargo, tuvo también consecuencias indeseadas como la distorsión del sistema económico a través de una financiarización excesiva.
\end{abstract}

Palabras clave.- globalización, proceso de globalización, globalización financiera, financiarización

\section{Development and consequences of financial globalization}

Abstract.- The globalization process managed to open new spaces that favored the financial and economic expansion. This financial expansion resulted in economic growth during the nineties. The accumulated surplus capital, which were threatened by the depreciation, found opportunities for profitable investment in the expansion of the globalization process. However, it also had unintended consequences such as distortion of the economic system through an excessive financialization.

Keywords.- globalization, the globalization process, financial globalization, financialization 
A lo largo de las siguientes páginas analizaremos las consecuencias más importantes relacionadas con el proceso de globalización en el circuito financiero. Se pretende elaborar desde la metodología de la Sociología Histórica aplicada a las Relaciones Internacionales (Tilly, 1992; Wallerstein, 2007), un análisis histórico del proceso de integración del sistema financiero a nivel global a lo largo del período histórico de la Globalización. Como marco teórico tomaremos la teoría del sistema-mundo (Wallerstein, 2007; Arrighi, 2007) y distinguiremos en el sistema internacional un centro activo y dominante de una periferia pasiva y dominada. En cuanto al subsistema económico, lo representaremos acudiendo a los mecanismos por los cuales se mantiene el equilibrio de poder entre el centro y la periferia, derivado de las relaciones económicas y comerciales (Gowan ${ }^{1}$; Brenner ${ }^{2}$ ). En este equilibrio de poder, el desarrollo de los actores de la periferia está subordinado a los intereses de los actores del centro reproduciendo el esquema de lucha de clases propio del capitalismo. Para explicar su transición en el ámbito espacial desde lo local a lo global recurriremos a autores neo-marxistas (Harvey ${ }^{3}$; Robinson ${ }^{4}$; Teitelbaum ${ }^{5}$ ). También, nos referiremos a los estructuralistas (Strange ${ }^{6}$; Frank ${ }^{7}$ ) y a los principios elaborados por los teóricos de la teoría de la dependencia (Prebisch, ${ }^{8}$ Cardoso-Faletto ${ }^{9}$, Pizarro-Caputo ${ }^{10}$ ) para alcanzar una explicación sobre el funcionamiento del subsistema económico lo más completa posible. Además, recurriremos a los neo-keynesianos (Stiglitz ${ }^{11}$; Krugman ${ }^{12}$ ) para explicar las sucesivas crisis económicas del sistema y sus causas relacionadas con la contracción de la demanda.

Conceptualmente, en primer lugar, debemos definir muy claramente el concepto de Globalización. La versatilidad de este término ha terminado por generar una profunda confusión, incluso entre los científicos. Coloquialmente hablamos de la Globalización dotándola de una personalidad y por tanto de una capacidad de acción. Por ejemplo: "La Globalización está causando desigualdades". Este hábito es el responsable de la confusión, ya que la Globalización no es un agente, sino un proceso evolutivo o un desarrollo histórico, si se quiere. El concepto, Globalización, representa algo similar al concepto, "Renacimiento" o "Belle Epoque". No puede ser responsable de nada, ya que tan sólo es el período de tiempo en el que transcurren una serie de acontecimientos históricos que por sus características puede considerarse que comparten el mismo conjunto de causas.

Por tanto, no es la Globalización quien actúa, sino una serie de actores

$\begin{array}{ll}1 & \text { Gowan, 2000. } \\ 2 & \text { Brenner, 2003. } \\ 3 & \text { Harvey, 2007. } \\ 4 & \text { Robinson, 2007. } \\ 5 & \text { Teitelbaum, 2010. } \\ 6 & \text { Strange, 1999. } \\ 7 & \text { Frank, 1970. } \\ 8 & \text { Prebisch, 1981. } \\ 9 & \text { Cardoso/ Faletto, } 1984 . \\ 10 & \text { Pizarro/ Caputo, 1982. } \\ 11 & \text { Stiglitz, 2007. } \\ 12 & \text { Krugman, 2009. }\end{array}$

(c) EMUI Euro-Mediterranean University Institute | Universidad Complutense de Madrid | ISSN 1578-6730 Publicación asociada a la Revista Nomads. Mediterranean Perspectives | ISSN 1889-7231 
internacionales o nacionales que con su interacción originan los fenómenos que componen el sistema internacional y al que por un determinado período de tiempo hemos acordado por nombrar: Globalización. Desde mi punto de vista, identificaré a la Globalización como el período histórico que sucede al de la Guerra Fría y es en el que nos hallamos actualmente inmersos. Por ello, debemos ajustar el origen de este período histórico al final de la Guerra Fría, es decir a la caída del bloque soviético. Podemos tomar como referencia simbólica la caída del muro de Berlín en 1989, que marca el inicio de los acontecimientos que llevan hasta la desaparición de la Unión Soviética en 1991.

Para mayor precisión debemos establecer una distinción entre el concepto de Globalización y el de "oleadas globalizadoras ${ }^{13}$ " que se han sucedido a lo largo de la Historia. Con respecto a las oleadas globalizadoras, los historiadores coinciden en identificarlas, en el último milenio, en torno al siglo XIII, XVI, XIX y la actual ${ }^{14}$. Sin embargo, el concepto de Globalización se originó referido al momento actual y por ello me parece pertinente la precisión. Por tanto, hay que delimitar las características que pueden diferenciar a la Globalización del resto de oleadas globalizadoras previas en el tiempo.

Estas características vienen dadas por las facultades propias del "proceso de globalización". Debemos distinguir a este otro concepto y lo consideraremos como el término para referirnos al conjunto de cambios que caracterizan a la actual oleada globalizadora. El proceso de globalización es un proceso evolutivo económico, político y social que se desarrolla en el período histórico de la Globalización. En este proceso evolutivo confluye la acción de los diferentes actores globales que interactúan en una dinámica molecular en la que surgen focos de actividad, normalmente en torno a grandes ciudades, que son centros de producción o distribución y que están conectados entre sí por vías de comunicación ${ }^{15}$. Esta dinámica da lugar a fuerzas múltiples que se entrecruzan, a veces contrarrestándose y otras veces reforzando tendencias conjuntas. Este proceso tiende a expandirse por diferentes dinámicas internas: de tipo económico, por cuanto genera demanda de inversión y consumo, generando beneficios económicos; de tipo social y político, por efecto contagio e imitación de otros modelos de desarrollo "más exitosos" o por asimilación forzosa.

Si bien, cada oleada globalizadora traza su propio proceso de globalización, todas tienen características similares como la progresiva "aceleración del tiempo". Es decir, la aceleración del ritmo de vida, a medida que se reducen las distancias espaciales y varían las estructuras económicas y políticas ${ }^{16}$. Las principales características que diferencian a este proceso de los anteriores son la intensidad en la compresión del espacio y el alcance de la simultaneidad temporal. Debido al desarrollo de los transportes y las tecnologías de las comunicaciones, los actores comparten un ámbito espacial reducido y una

$\begin{array}{ll}13 & \text { Tilly, } 1992 . \\ 14 & \text { Wallerstein, } 2007 . \\ 15 & \text { Harvey, 2007. } \\ 16 & \text { Como explica Harvey, } 2007 .\end{array}$


misma secuencia temporal ${ }^{17}$. La principal característica que define a la Globalización, por tanto, es la interdependencia que se ha desarrollado en el planeta en las últimas décadas, debido al desarrollo de las tecnologías de la comunicación.

De nuevo, es preciso aclarar que esta acotación temporal del concepto no niega la existencia de procesos similares en las oleadas globalizadoras precedentes. Como suele corresponder a estos procesos, el actual se ha visto favorecido por un largo período de ausencia de grandes conflictos bélicos y estabilidad política ${ }^{18}$. Durante la Guerra Fría, la estabilidad provenía del equilibrio de poder entre las dos superpotencias y en la Globalización proviene del liderazgo indiscutible de Estados Unidos. Sin embargo, a medida que el sistema internacional transita hacia un orden multipolar, en el que varias potencias ganan poder y Estados Unidos cede terreno, el equilibrio del orden internacional se hace más inestable ${ }^{19}$.

Desde la Economía, se han trazado abundantes estudios que han identificado la Globalización con la ampliación del mercado a nivel global. Los estudios se han centrado en los nuevos intercambios comerciales a nivel global y la financiarización ${ }^{20}$ de la economía gracias a los nuevos avances tecnológicos y la desregulación reglamentaria. Los efectos de todos estos cambios sobre el sistema económico global son el objeto del debate entre los teóricos. Para Milton Friedmann ${ }^{21}$ y Robert Reich ${ }^{22}$ la iniciativa privada es más eficiente que la intervención estatal a la hora de fomentar un crecimiento económico estable. Por tanto, debe permitirse actuar libremente a los agentes económicos privados a nivel global para que generen riqueza y progreso, de lo que se beneficiará toda la población mundial. Jagdish Baghwati ${ }^{23}$ y Paul Krugman ${ }^{24}$ matizan este argumento. Defienden el libre comercio, pero están claramente en contra de la liberalización de los movimientos de capital a corto plazo, ya que producen inestabilidad en los mercados que puede tener efectos negativos en la generación de riqueza. Es necesario introducir ciertos controles a las entradas de capital a corto plazo para que no fomenten crisis financieras. Samir $\operatorname{Amin}^{25}$ y Joseph Stiglitz ${ }^{26}$ incluso defienden la necesidad de desconectarse parcialmente del comercio global de los países con economías más débiles, ya que las lógicas del mercado sin controles aumentan las desigualdades entre ricos y pobres, y generan situaciones de competencia imperfecta que impiden su desarrollo. Por supuesto, están en contra de la libre circulación de capitales.

\footnotetext{
17 Castells, 2001.

18 Gowan, 2000.

19 Arrighi/ Silver, 2000. Todd, 2003.

20 "Financiarización" es un concepto reciente empleado en la ciencia económica para referirse a la preponderancia del sector financiero sobre los demás sectores en el desarrollo de algunas economías modernas. El término proviene del concepto original en inglés: "financialization".

21 Friedman/ Friedman, 2008.

22 Reich, 1993.

23 Baghwati, 2005.

$24 \quad$ Krugman, 2009.

25 Amin, 2000.

26 Stiglitz, 2007.
} 


\section{La globalización financiera}

El proceso de globalización logró abrir nuevos espacios que favorecieron la expansión financiera y económica ${ }^{27}$. En un sistema capitalista es necesaria la existencia de espacios donde invertir de manera rentable y continua los beneficios obtenidos. De no ser así, la acumulación de riqueza puede estancarse y provocar el colapso del sistema. Los flujos de capital precisan estar en continuo movimiento para no devaluarse por efecto de la inflación ${ }^{28}$. Además, los propietarios del capital compiten entre sí por acumular mayores rentas. Todos estos factores hacen inevitable que todo el sistema, pero más en concreto el sistema financiero, tiendan a la expansión. Por ello, podemos considerar al proceso de globalización como un desarrollo expansivo del sistema.

Gracias a la dinámica desencadenada, se abrieron nuevos espacios geográficos (Europa Oriental, China, India, etc.), así como espacios sectoriales que fueron desregulados para permitir las inversiones privadas. De esta manera, los excedentes generados en la esfera capitalista pudieron traspasar las barreras geográficas de la Guerra Fría e invertirse en la producción e intercambio de mercancías o la construcción de infraestructuras dentro del nuevo espacio territorial globalizado 0 en sectores económicos que anteriormente estaban regulados y no permitían la inversión privada. Esta expansión financiera, como veremos más adelante, se tradujo en un crecimiento económico durante la década de los noventa. De esta manera, los excedentes de capital acumulados, que estaban amenazados por la depreciación, encontraron posibilidades de inversión rentable en la ampliación del proceso de globalización.

Como respuesta al estancamiento del sector industrial en el centro del sistema a finales de la década de los setenta, que había provocado una crisis de rentabilidad en todo el sistema económico ${ }^{29}$ de la Tríada ${ }^{30}$, los gobiernos de Estados Unidos, de Japón y de la Unión Europea procuraron estimular el sector financiero con el doble objetivo de facilitar la obtención de créditos que reactivasen el sector industrial y el consumo, y por otro lado, generar mayores beneficios a través del sector financiero. Con estos objetivos se emprendió una guerra contra la inflación y se desencadenó un proceso de desregulación del sector financiero. Con la desregulación se suprimieron las limitaciones que hasta entonces obstaculizaban a las corporaciones financieras el acceso a todo tipo de mercados. El principal efecto de la desregulación fue la eliminación de los controles de capitales, los cuales habían sido la principal herramienta de los gobiernos para asegurarse de que la actividad financiera se atuviera a las

$27 \quad$ Harvey, 2007.

28 La rentabilidad del capital depende de su capacidad para mantener una tasa de crecimiento mínima del 3\%. Por debajo de ese mínimo se considera que la inflación destruye su rentabilidad. Harvey, 2012. p. 111.

29 La economía en general vio disminuir su tasa de beneficio como consecuencia de la caída que se produjo en el sector industrial, lo que a su vez era consecuencia de la menor velocidad relativa con que aumentaban los precios en el sector industrial. Brenner, 2003. p. 50.

$30 \quad$ La tasa de beneficio en el sector privado entre 1965 y 1973 cayó aproximadamente un 20\% en el conjunto de las economías del G-7. Brenner, 2003. p. 51. 
necesidades de la industria nacional.

Durante los años ochenta, el gobierno de Estados Unidos impulsó una expansión financiera de alcance internacional con la firma de diferentes acuerdos con la Unión Europea y Japón, y la adopción de medidas liberalizadoras y desreguladoras de los mercados financieros que generaban condiciones favorables para una dilatación de la deuda pública y privada a nivel global $^{31}$. Esta estrategia perseguía evitar la depresión económica de los años setenta y restaurar la rentabilidad de la actividad económica en el centro del sistema internacional ${ }^{32}$. El derrumbe de la Unión Soviética y el comienzo de la Globalización permitieron la extensión de la expansión financiera a todo el planeta y el comienzo del proceso de globalización financiera.

El gobierno de Estados Unidos pensaba beneficiarse de la liberalización financiera, ya que a su entender proporcionaría un impulso decisivo a su política hegemónica. Los flujos financieros que se dirigieran hacia el mercado de capitales estadounidense permitirían cubrir el creciente déficit presupuestario del gobierno, y de paso, estimular la economía nacional. Por otro lado, Washington pensaba favorecer a las corporaciones financieras estadounidenses que desde los años setenta, y especialmente con la crisis del petróleo en $1973^{33}$, habían ido orientando una parte cada vez mayor de sus actividades hacia el extranjero, facilitándoles sus inversiones en otras economías nacionales gracias a la liberalización. El crecimiento económico de los años noventa favoreció la expansión de la globalización financiera.

En torno al sistema financiero, se formó una compleja red cibernética que alcanzó el ámbito global y por la que se desplazaba el dinero a la velocidad de la luz y bajo las únicas limitaciones que imponían el mecanismo de los precios y las operaciones de mercado. La desregulación financiera y la revolución de las tecnologías de la información permitieron la desmaterialización y una ubicuidad total de las finanzas. Los principales centros financieros se hallaban en el centro del sistema, en Estados Unidos, la Unión Europea y Japón. La globalización financiera tejió un circuito que integraba la bolsa de Londres con la bolsa de New York y la bolsa de Tokyo.

Por otro lado, la desregulación de los mercados financieros y el surgimiento de un circuito financiero organizado en red, compartido por todos los operadores financieros, permitiría la distribución de los excedentes financieros a cualquier rincón del globo, donde pudieran invertirse. La aplicación de las nuevas tecnologías informáticas transformó el funcionamiento de los mercados financieros, que incrementaron, de forma extraordinaria, la rapidez de las transacciones y su compensación y liquidación. Las transacciones diarias en el mercado de divisas aumentaron desde 15.000 millones de dólares en 1973 a

31 Las adquisiciones estadounidenses netas de acciones extranjeras en la bolsa subieron de 4.200 millones de dólares en 1985 a 13.700 millones en 1989. Reich, 1993. p. 141.

32 Entre 1985 y 1990, el mercado de valores de EEUU trepó hasta el 147\%. Reich, 1993. p. 141.

33 Los bancos estadounidenses canalizaron miles de millones de dólares procedentes de los beneficios de los productores petrolíferos, los llamados petrodólares, hacia préstamos dirigidos a los Estados de la periferia del sistema. Brenner, 2003. p. 56. 
tres billones de dólares a comienzos del siglo XXI, es decir 200 veces más en veinte $a_{n}$ os $^{34}$. A pesar de todo, el sistema financiero no logró resolver el problema de los tipos de cambio, que se mantuvieron inestables incluso entre las principales monedas, distorsionando de esa manera las reglas de la competencia internacional.

El sector financiero no comenzó con buen pie el período de la Globalización. La recesión de 1990-1991 dejó a las corporaciones financieras en una situación delicada. La acumulación de deudas de las corporaciones no financieras durante la década de los ochenta paralizaba el negocio del crédito, ya que los bancos no podían arriesgarse a conceder más préstamos en dicha situación. Después del estancamiento económico de los años ochenta y el consiguiente recorte de la inversión en capital, los prestamistas y especuladores sólo contaban con opciones limitadas. Sus oportunidades de obtener elevadas ganancias dependía de la redistribución más o menos forzada de la renta y la riqueza por medios políticos, a través de la acción del Estado.

El horizonte para las corporaciones financieras se despejó cuando en 1993 la FED comenzó a rebajar los tipos de interés. Esto permitió que dichas corporaciones pudieran endeudarse a corto plazo con bajos intereses y conceder créditos caros a largo plazo, reactivando el negocio de los préstamos. La política de austeridad del gobierno de Clinton, que había prometido equilibrar el presupuesto público, ofreció seguridad a los financieros de que la inflación no aumentaría y no recortaría sus beneficios. También como concesión al sector financiero, la FED subió los tipos de interés en 1994, cuando la economía estadounidense se estaba recalentando y podían subir los precios.

Además de las medidas del gobierno de Estados Unidos, el sector financiero se benefició de la recuperación del sector industrial a mediados de los noventa. La demanda de crédito por parte de este sector aumentó vigorosamente y las pérdidas cayeron en picado. Al mismo tiempo que prosperaba el negocio del crédito, por fin, las corporaciones financieras pudieron sacar la máxima ventaja de la desregulación que se había iniciado en los ochenta. Con unos balances bien saneados pudieron arriesgarse a realizar arriesgadas inversiones en cualquier rincón del mundo. Además, se aceleró la concentración en el sector a través de compras y fusiones ${ }^{35}$. Con este viento favorable, las corporaciones financieras comenzaron a obtener los beneficios más altos de su historia ${ }^{36}$ y la economía en su conjunto comenzó a experimentar una tendencia hacia la financiarización, en la que el sector financiero predominaba claramente sobre todos los demás sectores económicos.

Esta expansión financiera aumentó el volumen de la IDE que circulaba por el mundo $^{37}$. Buena parte de estas inversiones se dirigieron a los mercados de

34 Datos: de la Dehesa, 2004.

35 En EEUU la proporción de activos bancarios en manos de las 50 mayores corporaciones del sector pasó del 57\% en 1986 al 64\% en 1996. Brenner, 2003. p. 110.

36 Entre 1994 y 2000, los beneficios del sector financiero en EEUU se duplicaron. Brenner, 2009. p. 489.

37 En 1989, las inversiones transnacionales en acciones de estadounidenses, japoneses 
acciones de las corporaciones, lo cual incrementó su precio y favoreció el crecimiento de éstas ${ }^{38}$. Así fue, sobre todo, en los períodos de finales de los noventa y luego entre 2005 y 2007. A mediados de los años noventa, hubo otro impulso a la expansión financiera. Durante el gobierno de Clinton, en 1995, se firmó el Acuerdo del Plaza Inverso ${ }^{39}$ entre las potencias del G-7, que revitalizó la tendencia original y consolidó a Estados Unidos en el centro del sistema financiero internacional. Este primer ciclo expansivo finalizó con la crisis financiera derivada de la explosión de la burbuja que se había formado en torno al precio de los valores de las corporaciones dedicadas a las comunicaciones ("crisis punto.com") entre 2000 y 2001.

Posteriormente, entre 2002 y 2007, el gobierno de Bush impulsó otra expansión financiera que concentró las inversiones en torno a los activos inmobiliarios. Esta expansión culminó también con una crisis financiera derivada de otra burbuja de precios relacionada con los títulos bursátiles obtenidos en el mercado hipotecario. El tamaño de estas crisis financieras se fue incrementando a medida que lo hacía el volumen de capitales involucrados. Además, ejercieron un efecto acumulativo de contracción con respecto a las expansiones financieras. Lo sorprendente es que el colapso de las burbujas y las consiguientes recesiones no hicieron retroceder los beneficios del sector financiero. Los bajos tipos de interés y las ayudas gubernamentales mantuvieron a resguardo al sector financiero que pudieron prosperar a pesar del menor crecimiento y la disminución de la actividad económica.

\section{La libre circulación de capitales}

Cuando los capitales excedentarios no eran reinvertidos en el mismo lugar donde se generaban, por motivos de rentabilidad, entonces buscaban otros lugares donde encontrasen una inversión más rentable ${ }^{40}$ y así, escapaban a la devaluación. Por lo que el sistema financiero global estaba sometido a una continua necesidad de expansión y búsqueda de rentabilidad desde su creación. Precisamente, esta búsqueda de nuevos mercados donde invertir los capitales excedentarios es la fuerza que impulsa a todo el sistema económico y es el principal motor que expande el proceso de globalización con su asimilación de nuevos territorios e interconexión de centros de desarrollo que aporten nuevos activos e inversiones rentables.

La liberalización financiera permitió la libertad del movimiento de los capitales a nivel global, aunque el $75 \%$ de todo el flujo de capital productivo en 1995 se acumulaba en el centro del sistema ${ }^{41}$. El volumen de la IDE global pasó de 0,18

y alemanes se incrementaron un $20 \%$ sobre las del año anterior. Reich, 1993. p. 140.

38 En 1989, la inversión en acciones de corporaciones en mercados foráneos ascendió a 1,6 billones de dólares, cerca del 14,5\% de la transacción mundial de acciones. Reich, 1993. p. 140.

39 Se lo denomina así por ser una renovación de los términos acordados en el "Acuerdo del Plaza" en 1985.

40 Los especialistas en el sector hablan de la "norma del 15\%" para considerar rentable una inversión.

$41 \quad$ Navarro, 2000. p. 116. 
billones de dólares en 1989; a 0,33 billones en 1995; a 0,74 billones en 2000; a 0,93 billones en 2003; a 1,79 billones en $2007^{42}$; Es decir, se produjo casi un incremento del 100\% de la IDE a nivel global entre 1989 y 2007 . Esta alcanzó su máximo en el año 2007 y a partir del estallido de la burbuja inmobiliaria, la expansión se tornó en estabilización y más tarde en contracción con la crisis financiera del 2008. Este año la IDE global descendió a 1,68 billones de dólares ${ }^{43}$; a 1,20 billones en $2009^{44}$; y a 1,30 billones en $2010^{45}$.

Los acuerdos internacionales por la libertad de circulación de capitales dotaron al capital global de una amplia movilidad, que obligó a los Estados a competir por la captación de las inversiones y de los créditos. Pocos eran los elegidos, tan sólo los que ofrecían un rendimiento alto a las inversiones. El centro del sistema fue el principal beneficiado, tanto política como económicamente, de las expansiones financieras, ya que la mayor parte de la IDE se dirigía a los Estados del centro ${ }^{46}$. Principalmente, a Estados Unidos que ocupaba la posición central y a sus corporaciones que estaban mejor situadas en la competición para recibir los flujos de crédito global ${ }^{47}$. En concreto, en el período de 1991 a 1998, Estados Unidos recibió un total de 521.000 millones de dólares en IDE en comparación con los 270.000 millones que se invirtieron en la periferia del sistema ${ }^{48}$.

Las regiones de la periferia como Iberoamérica y Africa sufrieron la desventaja de tener que competir con los mercados estadounidenses para atraer las inversiones foráneas. Al principio de la década, Iberoamérica fue el destino favorito de las inversiones en la periferia, pero a medida que avanzaba el proceso de globalización, el Sudeste Asiático fue ganando preponderancia. En un primer momento, las inversiones en la periferia provenían mayoritariamente de los OIGs, como el FMI y el BM. En 1990, las inversiones privadas en la periferia tan sólo ascendían a 42.000 millones de dólares, mientras que el FMI y el BM superaban esa cifra. A partir de 1997, las tendencias cambiaron. El flujo de inversiones oficiales disminuyeron y los flujos privados se quintuplicaron con respecto al inicio de la década, hasta alcanzar los 256.000 millones de dólares ${ }^{49}$.

Por ejemplo, en 1999, diez Estados de la periferia recibieron, ellos solos, el $80 \%$ de la IDE dirigida a la periferia50. Los Estados de la periferia obtuvieron

$\begin{array}{lll}42 & \text { La cantidad supone más del 3\% del PIB mundial. } \\ 43 & \text { Un descenso del } 14 \% \text { con respecto al } 2007 . \\ 44 & \text { Un descenso del } 40 \% \text { con respecto al } 2007 . \\ 45 & \text { Son } \quad \text { dólares } & \text { de }\end{array}$
http://unctadstat.unctad.org/TableViewer/tableView.aspx?Reportld=89 (28/05/2011).

$46 \quad$ Durante 1999 el centro absorbió el 74\% de la IDE y los Estados de la periferia el 26\%. Palomo, 2008.

$47 \quad$ En la década de los noventa la afluencia de IDE a Estados Unidos aumentó de 30 mil millones de dólares en 1991; a 57 mil millones en 1995; 202 mil millones en 1998; y 275 mil millones en 1999. Esto significaba que ese Estado recibió la tercera parte de toda la IDE que se repartió en el mundo y el 43\% de la que se destinó al centro del sistema. Robinson, 2007. (p. 40).

$48 \quad$ Robinson, 2007.

$49 \quad$ Krugman, 2009.

50 Palomo, 2008. 
inversiones del centro cuando las diferencias en el coste de la mano de obra hacían rentable la producción en su territorio; o cuando la emergencia de sus clases medias podía provocar un auge de la demanda e incrementos de los beneficios en las ventas. Esto benefició a algunos Estados de la periferia que reunían estos requisitos indispensables para la inversión. Sin embargo, los Estados más atrasados que requerían mayores inversiones y un proceso de amortización de la inversión más prolongado, quedaron excluidos de la agenda de los inversores. Por otra parte, los flujos de dinero caliente podían entrar en las economías nacionales tan rápidamente como podían salir. La salida de estos capitales se convirtió, de hecho, en la principal causa que originaba el torbellino de las crisis financieras que se desarrollaron en el período de la Globalización.

El flujo de inversiones hacia New York impulsó la cotización del dólar, aliviando la tendencia de los tipos de interés y facilitando de nuevo el endeudamiento masivo. Japón y otros Estados del Sudeste Asiático fueron los principales inversores durante los años noventa. Tras la crisis del Sudeste Asiático, China se convirtió en el principal inversor. De esta forma, Estados Unidos se reafirmó como el pivote central de la actividad del sistema financiero internacional y como la potencia militar indispensable que aseguraba el orden. La hegemonía estadounidense era incuestionable, ya que el resto del mundo aceptaba este ordenamiento global y reconocía el papel central de Estados Unidos.

Es posible identificar varios aspectos novedosos en la distribución de la IDE de 2006 en adelante. Uno de ellos es la alta participación que han llegado a tener algunos Estados de la periferia. De tal modo que a partir de entonces, justamente cuando empezó lo que podemos llamar segundo ascenso vertiginoso de la inversión extranjera directa, la participación de estos Estados ha alcanzado cerca de la mitad en cuanto al ingreso de flujos de inversión. Estas inversiones proceden en buena parte de los llamados "fondos soberanos" ${ }^{\prime 1}$, que han acumulado ingresos gracias a la subida del precio de las materias primas. Buena parte de estas inversiones se han destinado a la compra de corporaciones en todo el mundo. Los fondos soberanos provenientes de China, Omán, Qatar y Singapur, entre otros, invirtieron en 2010 cerca de 12.000 millones de dólares en la adquisición de compañías eléctricas, petroleras, de transportes, comerciales y financieras, en países como Australia, Brasil, Canadá, Estados Unidos, el Reino Unido, Sudáfrica y Vietnam, entre otros. Se estima que de 2005 a 2011 estos fondos soberanos habían acumulado inversiones por casi 150.000 millones de dólares ${ }^{52}$.

La libre circulación de capitales se señaló como beneficiosa, ya que creaba canales a través de los cuales el dinero fluía y activaba la producción y el mercado, generando mayor riqueza y bienestar. Asimismo, saldrían ganando la gran mayoría de los ciudadanos del mundo, en tanto en cuanto pudieran tener acceso al crédito, ya que podrían acceder a mayores flujos de capital y a un coste menor, con lo que podrían endeudarse para consumir más e invertir en bienes duraderos. Otra ventaja que obtendrían los ciudadanos del mundo sería

51 Fondo de inversión que pertenece a un Estado o un Banco Central.

52 Lorente/ Capella, 2009. 
en su faceta como consumidores de bienes y servicios, ya que gracias a la creciente competencia, podrían acceder a comprar un mayor número de bienes y servicios, de mejor calidad y a menor precio, que los que conseguían antes de expandirse la globalización financiera. Esto haría que mejorasen su renta disponible y su capacidad de compra y salieran claramente beneficiados ${ }^{53}$.

Sin embargo, el desigual acceso al crédito se convirtió en un rasgo característico del sistema global financiero. Sus consecuencias sobre los niveles de desarrollo de las diferentes sociedades es palpable. Por otra parte, la armonización de los mercados financieros está muy lejos de ser una realidad, como lo demuestra la volátil convergencia de los tipos de interés ${ }^{54}$. Por lo que, la desregulación fomentó el auge de las inversiones especulativas, como veremos más adelante, que aprovechaban los diferenciales de precios para obtener rentabilidad. De tal forma que la expansión financiera, que fue beneficiosa para el sistema durante la década de los noventa, se convirtió en perniciosa al desviar sistemáticamente la inversión creadora hacia el atesoramiento y la especulación en un proceso de "financiarización ${ }^{55}$ " de la economía, como veremos también más adelante.

\section{Los agentes financieros y los nuevos instrumentos financieros}

La desregulación normativa del sector financiero favoreció la expansión del sistema financiero y el proceso de financiarización. Esta concomitancia se tradujo en dos hechos relevantes: La elevada concentración de las fuentes de liquidez internacional en manos de intermediarios privados y el surgimiento de multitud de nuevos productos financieros derivados que absorbían el esfuerzo inversor. La desregulación se tradujo también en un mayor grado de internacionalización de las corporaciones financieras.

La expansión financiera benefició a los agentes financieros, ya que surgieron nuevos huecos de mercado altamente rentables para los intermediarios financieros, encargados de canalizar y distribuir el crédito. El protagonismo que ganaron las grandes corporaciones financieras, actuando como agentes de la circulación del dinero, no se veía en este momento como un problema, sino al contrario. La mayor competencia e innovación financiera lograrían un mayor desarrollo de los mercados financieros y aumentaría el crecimiento potencial de las economías al reducir el coste del capital, al aumentar su rentabilidad y al reducir el riesgo por la diversificación de las inversiones. Sin embargo, los cambios en el mercado, especialmente el ascenso de fuentes alternativas de finanzas corporativas, erosionaron aún más los márgenes de beneficio de los

\footnotetext{
53 de la Dehesa, 2004.

54 La integración financiera se mide observando las salidas netas de los países exportadores de capital y las entradas netas de los países importadores. Otra forma, es ver cuanto representan las inversiones directas en el extranjero en relación con las inversiones directas nacionales.

55 La financiarización de la economía consiste en un proceso en el que el sector financiero comienza a dominar y determinar el funcionamiento del sector productivo. Esta nueva configuración de las relaciones entre ambos sectores es lo que se denomina como "financiarización de la economía".
} 
bancos tradicionales y favorecieron las práctica más arriesgadas.

Por tanto, de manera inadvertida, las corporaciones financieras pasaron a ocupar un lugar central en el sistema que hacía sombra a los propios Estados. Gracias a su posición distribuidora de las inversiones y de la libertad de acción que gozaban, podían interferir en las decisiones políticas de los gobiernos. Las corporaciones financieras gozaban de plena libertad a la hora de elegir donde invertir el dinero y sólo escogían los lugares más rentables. Con el argumento de que los inversores rehuían aquellos Estados que seguían políticas económicas y fiscales que mermasen la rentabilidad de su inversión o fueran inseguros económicamente, las corporaciones financieras tenían el poder de adjudicar financiación de una manera discrecional.

El papel mediador de las instituciones y las corporaciones financieras en este circuito global del dinero las dotó de un protagonismo relevante, ya que eran los agentes canalizadores de la financiación a nivel mundial. Los actores principales de este juego financiero fueron intermediarios financieros que han ido imponiendo, paso a paso, su propia estructura de márgenes entre costos y beneficios en las inversiones que realizan a lo ancho del planeta. Se trata, por tanto, de corporaciones financieras transnacionales organizadas en complejas redes y compitiendo entre $s^{56}$. Estas corporaciones están formadas por sociedades financieras internacionales, bancos, fondos de inversión, fondos de pensiones, compañías de seguros, sociedades de capital-riesgo, etc. pero también actúan en los mercados financieros otro tipo de corporaciones y agentes estatales. El conjunto de actividades económicas en el mundo depende en buena parte de las interacciones entre estos agentes.

Con la desregulación del sector, culminada por Clinton en Estados Unidos, se abrió la puerta a enormes conglomerados que combinaban la banca comercial, la inversión y los seguros. Numerosas corporaciones financieras comenzaron a conceder créditos y operar como bancos, por lo que se empezó a hablar de un "sistema bancario paralelo" o "sistema bancario en la sombra"57. Estas corporaciones ofrecían sus propios pagarés titulizados, de modo que el importe total de los préstamos bancarios en Estados Unidos pasó a ser sólo mínimamente superior al total de pagarés en circulación. En los años noventa, en Estados Unidos, el total de préstamos bancarios ascendía en su conjunto a 600.000 millones de dólares, mientras que el crédito en forma de pagarés titulizados representaba 550.000 millones de dólares ${ }^{58}$.

Mientras que el sistema bancario tradicional opera con mayor o menor transparencia y está sujeto a la regulación estatal, las operaciones del sistema bancario en la sombra son mucho menos claras. No poseen depósitos y no están catalogados como instituciones bancarias, por lo que no se someten a la

56 Sólo diez de estos "megaconglomerados financieros" controlan no menos del $75 \%$ del negocio de las plazas bursátiles de todo el mundo. Algunos de los nombres de estos fondos de inversión, fondos mutuos, fondos de pensión privados y compañías aseguradoras son: Fidelity, Scudder, Merrill Lynch, Oppenheimer, Putman Funds Management, March and McLennan Co., Soros Fund Management, Salomon Brothers Inc., Nomura Securities Co., Weston Bank, o las administradas por bancos como JP Morgan, CS First Boston y CityCorp.

$57 \quad$ Krugman, 2009. p. 170.

$58 \quad$ Strange, 1999. p. 52. 
regulación bancaria. Con lo que operan en un limbo legal que le ofrece una gran libertad de acción. Este sistema bancario en la sombra creció enormemente hasta asumir unas dimensiones considerables en los mercados monetario y de financiación. Por lo que aumentó espectacularmente la proporción de activos ajenos al sistema bancario tradicional.

Uno de los principales agentes que operan en el circuito financiero y que han cobrado protagonismo creciente en la Globalización son los fondos de inversión especulativos $^{59}$ ("hedge funds"). Sus operaciones son opacas, secretas y rozan la legalidad. Acaparan enormes capitales provenientes de sus clientes y de préstamos con los que operan en los mercados financieros efectuando maniobras especulativas que dejen altos beneficios. La forma en que lo hacen consiste básicamente en apostar a la baja ("ir cortos") en algunos activos, en los que se han comprometido a entregarlos a un precio prefijado en alguna fecha futura, y apostar al alza ("ir largos") en otros activos ${ }^{60}$. Los beneficios se obtienen si cae el precio de los activos cortos, de tal manera que pueden entregarse a un precio más bajo, o aumenta el de los activos adquiridos, 0 ambas cosas a la vez ${ }^{61}$.

Los hedge funds pueden ofrecer un rendimiento muy alto a sus clientes. La razón estriba en que el fondo puede tomar una posición mucho mayor que la suma de dinero que los inversores depositan en él, porque compra su posición "larga" principalmente con la liquidez obtenida creando su posición "corta". El aspecto negativo está en que un hedge fund puede perder dinero muy fácilmente. Las maniobras especulativas más rentables son las más arriesgadas. A pesar de haber tomado garantías y precauciones, los movimientos del mercado son impredecibles y pueden destruir las previsiones del especulador. Si se producen pérdidas, los clientes pedirán retirar su dinero cuanto antes y esto significará la quiebra del fondo.

En 2006, se calcula que los hedge funds ya acaparaban la mitad de las transacciones bursátiles. Operan desde los paraísos fiscales y de manera muy activa y agresiva en las bolsas internacionales a la búsqueda de mínimos cambios de rentabilidad en los valores que produzcan beneficios. Fundamentalmente, operan con dinero prestado por los bancos y que han obtenido por medio de créditos que pueden llegar a ser 250 veces superior a sus propios fondos. Son los mayores operadores financieros y económicos tanto en beneficios como en hundimientos espectaculares que han arrastrado a corporaciones, bancos centrales y economías nacionales. Se estima que sus activos se multiplicaron por 3,6 entre 1990 y finales de 2006. Se hallan en el vértice mismo de la estructura financiera global.

Para poder financiar la expansión del proceso de globalización, los agentes financieros innovaron en nuevos instrumentos financieros más complejos que

59 Algunos de los más famosos son: The Carlyle Group, KKR, The Blackstone Group, Colony Capital, Apollo Management, Partners Cerberus, Starwood Capital, Texas Pacific Group, Wendel, Eurazeo, etc.

60 En terminología de los inversores, "ir largo en algo" significa apostar al alza del precio de algo. "Ir corto en algo" significa apostar a la baja del precio de algo. Krugman, 2009. p. 126.

61 Krugman, 2009. p. 126. 
permitían aumentar el endeudamiento. Estos instrumentos, cada vez más complejos, añadieron nuevas posibilidades a la actividad especulativa. En primer lugar, la titulación se hizo más compleja. Permitía sacar paquetes de crédito de los balances bancarios, traspasando el riesgo a los inversores que los compraban. A cambio, el inversor podía obtener mayores rentabilidades y el banco una sustanciosa comisión. Desde entonces, apareció un nuevo negocio distinto a conceder créditos contrastados para poder ser cobrados. El nuevo negocio consistía en vender los créditos transformados en títulos, prescindiendo del riesgo para el banco.

La inversión y la titularización de activos financieros ${ }^{62}$ fue la oferta que el capitalismo financiero planteó a los ahorradores. Poco a poco, los bancos experimentaron un visible descenso en la actividad y las ganancias por concesión de créditos y un aumento en las operaciones y los beneficios por el comercio de títulos ${ }^{63}$. Los bancos pasaron de ser fuente de crédito en el sistema a ser también consultores y asistentes de gestión financiera. Desde la década de los noventa, la esfera financiera se ha desligado de la economía real. Se estima en más de 28 billones de dólares el conjunto de las diferentes actividades financieras internacionales en este período, de los cuales más de 12 billones son acciones y obligaciones; más de 8 billones son stocks de préstamos bancarios y casi 7 billones son IDE ${ }^{64}$.

Las corporaciones financieras también apostaron por los productos derivados. Surgieron multitud de nuevos productos financieros derivados que se ofertaban como posibilidad rentable de inversión. Los derivados, de los que existe una amplia gama de productos, son básicamente contratos de seguros para instrumentos financieros. A cambio de una prima, el vendedor asegura al comprador sobre determinadas vicisitudes, como impago, quiebra del emisor, disminución del valor de cotización, y otros de mayor complejidad ${ }^{65}$. Normalmente, estos seguros son ofrecidos por las grandes corporaciones aseguradoras, pero los pueden ofrecer también los hedge funds y los bancos de inversión. Los derivados son una forma sofisticada de gestionar el riesgo y su importancia ha crecido al tiempo que se multiplicaban tanto los riesgos como el número de víctimas potenciales del riesgo.

A medida que crecía el comercio internacional, también aumentó el número de corporaciones que necesitaban tener acceso a divisas y préstamos extranjeros. Pero a la par que surgía dicha demanda, también se incrementaba el riesgo de que los beneficios pudiesen desaparecer por oscilaciones imprevisibles de los tipos de cambio, en los tipos de interés o en los precios de los productos. El negocio de derivados ofreció a los bancos y demás corporaciones una oportunidad, a un coste relativamente bajo, para cubrirse contra las pérdidas

62 La "titularización" es la creación de títulos financieros a partir de diferentes productos que luego se cotizarán en el mercado de capitales y, por tanto, comprados y vendidos en forma de activos.

$63 \quad$ Estos títulos los ofertan las empresas en la bolsa y son comprados y vendidos por los diferentes agentes financieros.

$64 \quad$ Lorente/ Capella, 2009.

65 Strange, 2003. 
provocadas por estas oscilaciones ${ }^{66}$. En marzo de 1995, el valor de los contratos de derivados en veintiséis Estados se estimaba en el doble del valor de la producción económica global, unos 47,5 billones de dólares ${ }^{67}$. Las sumas teóricamente aseguradas por estos derivados sumaban en Estados Unidos 500.000 millones de dólares en el 2000 y en 2008 alcanzaron los 55 billones. Es decir, el PIB mundial de ese año ${ }^{68}$.

Pero además, los contratos derivados ofrecían otro atractivo para los inversores, unas buenas oportunidades de beneficio. La innovación de los contratos derivados no estaba sujeta a regulaciones y a impuestos. Los contratos de derivados se realizaban "over the counter", es decir, fuera de los mercados bursátiles. Estos contratos se negociaban directamente entre las dos partes sin ningún tipo de regulación y bajo las condiciones que los contratantes decidieran. En poco tiempo, este tipo de contratos duplicó al efectuado dentro de los márgenes de los mercados bursátiles. En 1995, el volumen de los contratos "over the counter" en todo el mundo se calculaban en casi 18 billones de dólares y en 1996 ya alcanzaban los 24 billones de dólares ${ }^{69}$.

Estas operaciones financieras son las menos transparentes de todas. La ignorancia sobre estas transacciones es una de las principales causas que arrojan incertidumbre sobre la situación de los mercados. Como no hay un registro de estas operaciones, es imposible conocer el grado de exposición de los agentes. Esta incertidumbre ha jugado un papel crucial en las crisis financieras del siglo XXI, ya que era imposible determinar el verdadero riesgo implícito de las inversiones realizadas, lo que generaba desconfianza entre los inversores. Esta desconfianza manifiesta se traduce en bajos niveles de inversión en momentos de crisis.

Los gobiernos perdieron el control sobre los nuevos instrumentos crediticios. La ausencia de una regulación que acotase determinados comportamientos dejó la puerta abierta a que se contrajesen deudas en cualquier moneda. Por vinculación, el hundimiento de las cotizaciones de los deudores privados se podía convertir en el hundimiento de una moneda nacional. Por tanto, las deudas privadas eran fácilmente convertidas en públicas con el nuevo juego financiero. La propia dimensión de los rescates financieros mostraba cómo se había acrecentado el problema, hasta el punto de generar la quiebra de numerosos Estados. Por otra parte, el sistema económico no ha desarrollado normas generales para el tratamiento de los Estados insolventes. Mientras que en los negocios privados existe la consideración de que las inversiones puedan fracasar debido a diversos motivos y se admite la posibilidad de una quiebra reconocida legalmente, en el caso de los Estados no existe tal regulación ${ }^{70}$.

A pesar de todo, gracias a estos instrumentos financieros se habían creado

$66 \quad$ Strange, 1999. p. 45.

$67 \quad$ Strange, 1999. p. 44.

68 Lorente/ Capella, 2009. p. 47.

69 Strange, 1999. p. 44.

70 Sólo en parte se abordó este problema, de manera decepcionante, mediante el mecanismo de negociación de los MYRA (Multi-Year Rescheduling Agreements: Acuerdos de Reescalonamiento Plurianual de la Deuda) y mediante los SAL (Structural Adjustment Loans: Préstamos de Ajuste Estructural). 
nuevas herramientas de financiación. Mientras se incrementaba su oferta, aumentó la demanda y los gestores obtuvieron grandes beneficios. Las inmensas cantidades de crédito que precisaban las grandes corporaciones y los Estados proporcionaron a los bancos de inversión y demás corporaciones financieras nuevas y vastas oportunidades de generar beneficios. Estos beneficios, a su vez, repercutían en el alza de las cotizaciones en los mercados y en una abundancia de crédito barato. Durante el período de auge de la Globalización se mantuvo esta espiral ascendente con el resultado de una sobreabundancia de crédito en el sistema financiero ${ }^{71}$.

\section{Financiarización de la economía y conclusiones}

Además de la expansión financiera se produjo también un proceso de financiarización del sistema económico ${ }^{72}$. Este proceso consistió en una tendencia en la que el sector financiero comenzó a ser preponderante en el sistema económico. En Estados Unidos, por ejemplo, todavía en 1995, los beneficios del sector industrial suponían el $42 \%$ de los beneficios empresariales totales, y el $51 \%$ de los beneficios de las corporaciones no financieras. En 2006 , esas cifras habían caído al $30 \%$ y el $36 \%$ respectivamente $^{73}$. De hecho, en las economías del centro del sistema el sector financiero pasó a dominar y determinar el funcionamiento del sector productivo. Esta nueva configuración de las relaciones entre ambos sectores es lo que se denomina como financiarización de la economía ${ }^{74}$.

Las causas de esta tendencia pueden encontrarse en la gran rentabilidad que alcanzó la actividad financiera en comparación con la actividad industrial. Este incremento de la rentabilidad en el sector financiero surgió de una complicada combinación de tendencias. Por un lado, el desarrollo de las nuevas tecnologías de comunicación posibilitó la movilidad del capital a escala global, que en combinación con la desregulación provocó la expansión del sector financiero a escala global. Por otro lado, las innovaciones en nuevas herramientas financieras, como la titulación, permitió nuevas técnicas de inversión generaban más rentabilidad con el mismo volumen de inversión. Esta expansión y éxito del sector financiero generó una desvalorización de la actividad industrial y de los servicios de poco valor agregado. Por lo que se desplazó una mayor actividad económica de los agentes hacia el sector financiero en busca de una rentabilidad mayor ${ }^{75}$.

Debido a que el sistema económico experimentó este proceso de financiarización, se produjeron transformaciones en el funcionamiento del propio sistema económico. Al desplazarse el peso de la actividad hacia las finanzas, este sector, el de los seguros y el de la propiedad inmobiliaria sobrepasaron en beneficios totales a los obtenidos por el sector industrial durante la década de los noventa. En 1997, el volumen del comercio global era

\begin{tabular}{ll}
\hline 71 & Strange, 1999. \\
72 & Arrighi, 2007. \\
73 & Brenner, 2009. p. 90. \\
74 & Krippner, 2011. \\
75 & Sassen, 2010. p. 148.
\end{tabular}


de unos 3 billones de dólares, mientras que el flujo de capitales transnacionales era de 100 billones de dólares. Es decir, unas treinta veces más ${ }^{76}$. Las propias corporaciones no financieras aumentaron notablemente sus inversiones en activos financieros con respecto a las inversiones en instalaciones y equipos, pasando a depender, cada vez más, de fuentes financieras en la obtención de sus ingresos y beneficios en comparación con los obtenidos de sus actividades productivas.

A medida que ha avanzado la globalización financiera y la financiarización, se ha observado una clara tendencia de los capitales hacia la inversión especulativa, en detrimento de la productiva ${ }^{77}$. Ello se explica por los mayores índices de rentabilidad que suelen ofrecer las actividades especulativas y porque las inversiones productivas requieren inversiones a largo plazo, en los que los beneficios se demoran largo tiempo, mientras que las inversiones especulativas son a corto plazo y los beneficios se obtienen en poco tiempo78. De tal manera que se puede diferenciar entre inversiones de corto plazo e inversiones de largo plazo79. Por lo general, las inversiones a largo plazo son inversiones productivas con rendimientos futuros. Las inversiones a corto plazo son, fundamentalmente, operaciones de tipo especulativo, que aprovechan resquicios del sistema para obtener beneficios en un breve espacio de tiempo.

Por tanto, la actividad productiva de manufacturas u otro tipo de actividades económicas clásicas se enfrentan a exigencias de rentabilidad muy severas en competencia con las actividades especulativas. Este hecho no favorece la calidad de los productos o servicios ofrecidos. De manera que se da la paradoja de que los aumentos de productividad resultantes de las nuevas tecnologías y de la innovación no se traduce necesariamente en un beneficio satisfactorio. Las grandes corporaciones inmersas en una carrera competitiva a vida o muerte buscan la mayor rentabilidad posible para sus beneficios.

Es por ello, que invierten cantidades, cada vez mayores, de capital en los circuitos financieros, en busca de inversiones con más rentabilidad, en lugar de reinvertirlo en sus propios negocios. Las corporaciones saltaron a la bolsa ofertando sus propias acciones y por otro lado, invertían sus beneficios también en la bolsa. El beneficio financiero que obtienen con estas inversiones sirve para llenar el vacío que supone el riesgo de no lograr rendimiento alguno con las actividades de producción y de comercio. Tener capitales inmovilizados en inversiones a largo plazo resta competitividad a la corporación. Por tanto, la tendencia especulativa de las inversiones no implica la creación de nueva

$76 \quad$ Amin, 2000. p 120.

77 Se calcula que desde el colapso del acuerdo de Bretton Woods (1972) hasta el comienzo del siglo XXI, un $88 \%$ de todas las transacciones financieras, a escala mundial, habían sido de tipo especulativo, mientras que antes de aquel suceso, el $90 \%$ de las transacciones correspondían a intercambios comerciales y a inversiones productivas. Harvey, 2007.

78 El 80\% de los dos trillones de dólares que traspasaron fronteras en 1998 eran transacciones de una semana o menos. Harvey, 2007.

79 También se los llama: "Flujos de dinero calientes" (movimientos rápidos con rendimientos a corto plazo, muy sensibles a los cambios en el mercado). "Flujos de dinero fríos" (inversiones con rendimientos a largo plazo, pero más sólidos ante los cambios en el mercado). 
riqueza tangible sino simplemente la inflación del precio de los activos ya existentes.

En los Estados del centro del sistema, la demanda por bienes manufacturados está siendo desplazada por la demanda de servicios. Con respecto a los servicios, por lo general, son posibles menores mejoras de productividad, y por consiguiente, menores perspectivas de ganancia, lo cual hace huir a los capitales hacia otro tipo de inversiones más rentables. A nivel global, las exigencias desmesuradas de rentabilidad, disminuyen el interés por la actividad productiva y provocan un efecto de expulsión que hace que cierto número de producciones $\mathrm{y}$, por tanto, de necesidades sociales que éstas podrían satisfacer, no sean ya elegibles considerando los criterios de hiper-rentabilidad a los que se enfrentan.

Además, la búsqueda de incremento en los beneficios, sumado a la competitividad, no hace mas que perpetuar el problema de la sobreacumulación de capitales que deben buscar incesantemente rentabilidad, pero también explica dos consecuencias no deseadas: Una es la tendencia de las inversiones hacia las actividades especulativas, en detrimento de las productivas, ya que las corporaciones han puesto en juego grandes masas de capital buscando beneficios más rápidos, sin tener en cuenta que una vez apostados dichos capitales será muy difícil sustraerlos a la dinámica de los flujos del mercado ${ }^{80}$. De hecho, el sistema financiero global ya sólo puede seguir funcionando si se mantiene el ingreso incesante de nuevas inversiones 0 activos al esquema piramidal de negocio en que se ha convertido ${ }^{81}$.

Otra es que, cuando el espacio se ha copado y las posibilidades de inversión rentable se han reducido, los actores financieros pueden actuar para generar, artificialmente, nuevos espacios de inversión rentable. Es decir, intervenir en el mercado para provocar una crisis financiera. Sin embargo, estas actuaciones, con vistas a provocar desequilibrios económicos que puedan hacer más rentables las inversiones, son otra fuerza generadora de inestabilidad en el sistema económico, ya que la explotación de estas fisuras de desequilibrio económico pueden agrandar las desigualdades o provocar crisis económicas con pérdida de las inversiones. Por tanto, la misma energía que representan las inversiones financieras en el sistema económico puede operar como constructiva o destructiva.

La propia competencia entre los agentes financieros hizo que cada vez fuera más difícil ganar dinero. Para obtener alta rentabilidad los fondos de inversión debían adoptar operaciones más complejas e ingeniosas, pero con mayores riesgos. Al mismo tiempo, el proceso de concentración en el sector financiero había creado enormes fondos de inversión que acaparaban ingentes activos del mercado. Cuando uno de estos fondos ponía a la venta un determinado grupo de activos, podía provocar la caída de su precio, al inundar de oferta el mercado. La competencia entre los agentes financieros y el debilitamiento de la economía global por las sucesivas recaídas en episodios de crisis financiera,

80 Alonso/ Fernández de Lis/ Steinberg, 2009.

81 Es difícil determinar a partir de qué momento histórico el sistema se convirtió en una estructura piramidal. Esta tarea se la dejaremos a los economistas. 
estrechó las oportunidades para los inversores y disparó las primas de riesgo y los créditos hasta niveles desconocidos en la Globalización.

La principal consecuencia de la globalización financiera en el ámbito político fue que propició el surgimiento de nuevas configuraciones de poder, que socavaron el poder de los Estados. La consecuencia en lo social fue que produjo dislocaciones sociales que provocaron movimientos de resistencia y rebelión protagonizados por los grupos más perjudicados económicamente. Por tanto, en última instancia la globalización financiera exacerbó la competencia económica, ya que la búsqueda de incremento en los beneficios, sumado a la competitividad, no hizo mas que dotar de una personalidad nómada al problema de la sobreacumulación de capitales. Ahora los inversores debían buscar incesantemente rentabilidad a lo largo del circuito financiero. Pero además, atizó los conflictos sociales y las rivalidades interestatales hasta niveles que amenazaban sobrepasar la capacidad hegemónica del centro del sistema.

La financiarización de la economía y el protagonismo adquirido por los mercados bursátiles y los agentes del sistema financiero desde los años noventa son un síntoma del debilitamiento de la hegemonía estadounidense ${ }^{82}$. Estados Unidos se ha hecho en extremo dependiente de la financiación proveniente de los mercados financieros, lo cual le impide regular y exigir un orden en el sistema de relaciones de las grandes corporaciones financieras. La crisis económica global (2009-2010) es una clara consecuencia de todo este desorden sistémico. La financiarización de la economía y la inestabilidad que la acompaña han generado una masiva redistribución de las rentas y la riqueza. Esta redistribución tiende a ser, cada vez, más desigual polarizando a la sociedad internacional. Por lo que hace que el sistema internacional sea menos sostenible económica, social y políticamente.

82 Para Arrighi, estos procesos de financiarización de la economía señalan el comienzo de las crisis hegemónicas y se corresponden con la decadencia de la potencia líder del sistema. Arrighi, 2007. 


\section{Bibliografía}

A Alonso, José Antonio/ Fernández de Lis, Santiago/ Steinberg, Federico (2009). La Reforma de la Arquitectura Financiera Internacional. Biblioteca Nueva.

A Amin, Samir (2000). El capitalismo en la era de la Globalización. Paidos.

A Arrighi, Giovanni (2007). Adam Smith en Pekín. Akal. Madrid.

A Arrighi, Giovanni/ Silver, Beverly J. (2000). Caos y orden en el sistemamundo moderno. Akal. Madrid.

A Baghwati, Jagdish (2005). En defensa de la Globalización. Debate. Madrid.

A Brenner, Robert (2009). La economía de la turbulencia global. Akal. Madrid.

- (2003). La expansión económica y la burbuja bursátil. Akal. Madrid.

A Castells, Manuel (2001). La Era de la Información. Vols. I, II y III. Alianza. Madrid.

A Dehesa, Guillermo de la (2004). Comprender la Globalización. Alianza Edt. Madrid.

A Friedmann, Milton/ Friedmann, Rose (2008). Libertad de elegir. FAES. Madrid.

A Gowan, Peter (2000). La apuesta por la Globalización. Akal. Madrid.

A Harvey, David (2012). El enigma del capital. Akal. Madrid.

- (2007). El nuevo imperialismo. Akal. Madrid.

A Krippner, Greta R. (2011). Capitalizing on Crisis: The Political Origins of the Rise of Finance. Harvard University Press.

A Krugman, Paul (2009). El retorno de la economía de la depresión. Editorial Crítica.

A Lorente, Miguel Angel/ Capella, Ramón (2009). El crack del año ocho. Trotta. Madrid.

A Navarro, Vicenç (2000). Globalización económica, poder político y Estado del Bienestar. Ariel. Barcelona.

A Palomo, Aleksandro (2008). La crisis de los valores en la Globalización. VDM. Saarbrücken.

A Reich, Robert B. (1993). El trabajo de las naciones. Vergara edt. Buenos Aires.

A Robinson, William I. (2007). Una teoría sobre el capitalismo global. Desde abajo. Bogotá.

A Sassen, Saskia (2010). Una sociología de la globalización. Katz. Buenos Aires. 
A Stiglitz, Joseph (2007). El malestar de la Globalización. Punto de Lectura.

A Strange, Susan (2003). La retirada del Estado. Icaria. Barcelona.

- (1999). Dinero loco: el descontrol del sistema financiero global. Paidós. Barcelona.

A Tilly, Charles (1992). Coerción, capital y los Estados europeos, 9901990. Alianza. Madrid.

A Todd, Emmanuel (2003). Después del imperio. Foca. Madrid.

A UNCTAD,

2010.

http://unctadstat.unctad.org/TableViewer/tableView.aspx?Reportld=89 (28/05/2011).

A Wallerstein, Immanuel. (2007). El moderno sistema mundial I, II, III. Siglo XXI. México D.F. 